\title{
Methanotrophic activity and diversity of methanotrophs in volcanic geothermal soils at Pantelleria (Italy)
}

\author{
A. L. Gagliano ${ }^{1,2}$, W. D’Alessandro ${ }^{3}$, M. Tagliavia ${ }^{2, *}$, F. Parello ${ }^{1}$, and P. Quatrini ${ }^{2}$ \\ ${ }^{1}$ Department of Earth and Marine Sciences (DiSTeM), University of Palermo, Via Archirafi 36, 90123 Palermo, Italy \\ ${ }^{2}$ Department of Biological, Chemical and Pharmaceutical Sciences and Technologies (STEBICEF), \\ University of Palermo, Viale delle Scienze, Bldg 16, 90128 Palermo, Italy \\ ${ }^{3}$ Istituto Nazionale di Geofisica e Vulcanologia (INGV) Sezione di Palermo, Via U. La Malfa 153, 90146 Palermo, Italy \\ * present address: Istituto per l'Ambiente Marino Costiero (CNR-IAMC) U.S.O. of Capo Granitola, Via del Mare 3, \\ Torretta-Granitola, Mazara, Italy
}

Correspondence to: W. D’Alessandro (walter.dalessandro@ingv.it)

Received: 12 February 2014 - Published in Biogeosciences Discuss.: 1 April 2014

Revised: 4 September 2014 - Accepted: 14 September 2014 - Published: 22 October 2014

\begin{abstract}
Volcanic and geothermal systems emit endogenous gases by widespread degassing from soils, including $\mathrm{CH}_{4}$, a greenhouse gas twenty-five times as potent as $\mathrm{CO}_{2}$. Recently, it has been demonstrated that volcanic or geothermal soils are not only a source of methane, but are also sites of methanotrophic activity. Methanotrophs are able to consume 10-40 Tg of $\mathrm{CH}_{4} \mathrm{a}^{-1}$ and to trap more than $50 \%$ of the methane degassing through the soils. We report on methane microbial oxidation in the geothermally most active site of Pantelleria (Italy), Favara Grande, whose total methane emission was previously estimated at about $2.5 \mathrm{Mg} \mathrm{a}^{-1}\left(\mathrm{ta}^{-1}\right)$. Laboratory incubation experiments with three top-soil samples from Favara Grande indicated methane consumption values of up to $59.2 \mathrm{nmol} \mathrm{g}^{-1}$ soil d.w. $\mathrm{h}^{-1}$. One of the three sites, FAV2, where the highest oxidation rate was detected, was further analysed on a vertical soil profile, the maximum methane consumption was measured in the topsoil layer, and values greater than $6.23 \mathrm{nmol} \mathrm{g}^{-1} \mathrm{~h}^{-1}$ were still detected up to a depth of $13 \mathrm{~cm}$. The highest consumption rate was measured at $37^{\circ} \mathrm{C}$, but a still detectable consumption at $80^{\circ} \mathrm{C}\left(>1.25 \mathrm{nmol} \mathrm{g}^{-1} \mathrm{~h}^{-1}\right)$ was recorded. The soil total DNA extracted from the three samples was probed by Polymerase Chain Reaction (PCR) using standard proteobacterial primers and newly designed verrucomicrobial primers, targeting the unique methane monooxygenase gene $p m o A$; the presence of methanotrophs was detected at sites FAV2 and FAV3, but not at FAV1, where harsher chemical-physical conditions and negligible methane oxi-
\end{abstract}

dation were detected. The $p m o A$ gene libraries from the most active site (FAV2) pointed to a high diversity of gammaproteobacterial methanotrophs, distantly related to Methylocaldum-Metylococcus genera, and the presence of the newly discovered acido-thermophilic Verrucomicrobia methanotrophs. Alphaproteobacteria of the genus Methylocystis were isolated from enrichment cultures under a methane-containing atmosphere at $37^{\circ} \mathrm{C}$. The isolates grow at a $\mathrm{pH}$ range of 3.5 to 8 and temperatures of $18-45^{\circ} \mathrm{C}$, and consume $160 \mathrm{nmol}$ of $\mathrm{CH}_{4} \mathrm{~h}^{-1} \mathrm{~mL}^{-1}$ of culture. Soils from Favara Grande showed the largest diversity of methanotrophic bacteria detected until now in a geothermal soil. While methanotrophic Verrucomicrobia are reported as dominating highly acidic geothermal sites, our results suggest that slightly acidic soils, in high-enthalpy geothermal systems, host a more diverse group of both culturable and uncultivated methanotrophs.

\section{Introduction}

Methane plays an important role in the earth's atmospheric chemistry and radiative balance, being the second most important greenhouse gas after carbon dioxide. It is released into the atmosphere by a large number of sources, both natural and anthropogenic, with the latter being twice as large as the former (IPCC, 2001). It has recently been established that significant amounts of geologic $\mathrm{CH}_{4}$, produced within 
the earth's crust, are currently released naturally into the atmosphere (Etiope et al., 2008). Volcanic/geothermal systems emit endogenous gases, including $\mathrm{CH}_{4}$, by widespread degassing from soils. Indirect estimations based on $\mathrm{CO}_{2}$ or $\mathrm{H}_{2} \mathrm{O}$ outputs and $\mathrm{CO}_{2} / \mathrm{CH}_{4}$ or $\mathrm{H}_{2} \mathrm{O} / \mathrm{CH}_{4}$ ratios of the main gas manifestations gave a total $\mathrm{CH}_{4}$ emission from European geothermal/volcanic systems in the range of 4$16 \mathrm{Gg} \mathrm{a}^{-1}$ (4000-16000 ta ${ }^{-1}$ ) (Etiope et al., 2007). Methanotrophy is a metabolic process by which bacteria obtain energy via the oxidation of $\mathrm{CH}_{4}$ to $\mathrm{CO}_{2}$ (Murrell and Jetten, 2009). Methanotrophs are a subset of methylotrophic bacteria that use methane as the sole $\mathrm{C}$ source (Hanson and Hanson, 1996). They are abundant at the anoxic-oxic interfaces of methanogenic environments such as wetlands, peatlands (Kip et al., 2012), aquatic sediments (Rahalkar et al., 2009), landfills (Ait-Benichou et al., 2009) and, as recently discovered, also in geothermal areas, which have long been considered incompatible with methanotrophic activity (Op den Camp et al., 2009). Methanotrophy in soils is one of the main sinks of atmospheric methane; methanotrophs are able to consume 10 to $40 \mathrm{Tg}$ of $\mathrm{CH}_{4} \mathrm{a}^{-1}$ and to trap more than $50 \%$ of the methane degassing through the soils (IPCC, 2001; Reeburgh, 2003). The effectiveness of biological oxidation processes within the soil depends not only on the type and quantity of methanotrophic microorganisms, but also on the characteristics of the soils. Dry soils with high permeability and circumneutral $\mathrm{pH}$ favour methanotrophic activity consuming the atmospheric $\mathrm{CH}_{4}$ efficiently (Hanson and Hanson, 1996; Op den Camp et al., 2009). In such a situation, methanotrophic activity is sustained by a $\mathrm{CH}_{4}$ flux coming from the atmosphere above the soil, but this activity can also be sustained by $\mathrm{CH}_{4}$ fluxes coming from below. Such a flux can be of biological origin $\left(\mathrm{CH}_{4}\right.$ production in deeper anoxic layers) or of more deeper geogenic origin in areas rich in hydrocarbon reservoirs, or in geothermal/volcanic areas. In these cases, the $\mathrm{CH}_{4}$ flux often exceeds the biologic oxidation capacity, and soils become a source of endogenous $\mathrm{CH}_{4}$ for the atmosphere (Cardellini et al., 2003; Castaldi and Tedesco, 2005; D'Alessandro et al., 2009, 2011; Etiope and Klusman, 2010). Methane flux measurements in volcanic/geothermal areas, starting in recent years (Etiope and Klusman, 2002; Castaldi and Tedesco, 2005), accounted for a new, previously neglected, source of atmospheric $\mathrm{CH}_{4}$. Castaldi and Tedesco (2005) hypothesised for the first time the presence of methanotrophic microorganisms in such areas. Actually, soon after, a new group of obligately methanotrophic bacteria was isolated from different geothermal/volcanic sites and affiliated with the Verrucomicrobia phylum. These new isolates thrive at very low $\mathrm{pH}$ (down to 0.8 ) and high temperatures (up to $60^{\circ} \mathrm{C}$ optimal temperature), and may consume $10-90 \%$ of the methane before its emission from soils (Pol et al., 2007; Islam et al., 2008; Dunfield et al., 2007). Before the discovery of the methanotrophic Verrucomicrobia that are affiliated with the Methylacidiphilaceae fam- ily, known methanotrophic bacteria were taxonomically affiliated with the Proteobacteria phylum in the Gammaproteobacteria and Alphaproteobacteria classes. Among proteobacterial methanotrophs, type I methane-oxidising bacteria use the ribulose monophosphate pathway for formaldehyde fixation, while type II methane-oxidising bacteria use the serine pathway. Type $\mathrm{X}$ methanotrophs are similar to type I methanotrophs, but they also have low levels of enzymes of the Ribulose 1,5-bisphosphate carboxylase (RuBisCO) serine pathway, an enzyme present in the CalvinBenson cycle (Hanson and Hanson, 1996). Type I and type II are sometimes used as synonyms for Gamma- and Alphaproteobacteria, respectively (Op den Camp et al., 2009), and type $\mathrm{X}$ methanotrophs have been included, together with type I, in the Methylococcaceae family (Gammaproteobacteria) (Wise et al., 1999). The RuBisCO pathway is used by Verrucomicrobia Methylacidiphilum fumarolicum to fix $\mathrm{CO}_{2}$ using $\mathrm{CH}_{4}$ as an energy source (Khadem et al., 2011).

Methanotrophic communities in natural areas can be investigated and characterised using functional genes such as pmoA and mmoX (McDonald et al., 2008) encoding subunits of the two forms of the methane monooxygenase enzyme (the particulate $\mathrm{pMMO}$ and the soluble sMMO, respectively), which catalyses the first step in the methane oxidation pathway and can only be found in methanotrophs (Hanson and Hanson, 1996).

Italy is a geodynamically active region with several active volcanic/geothermal areas, including Pantelleria. Previously, D'Alessandro et al. (2009) estimated a total methane output at Pantelleria of close to $10 \mathrm{Mg} \mathrm{a}^{-1}\left(\mathrm{t} \mathrm{a}^{-1}\right)$. The same authors suggested the presence of methanotrophic activity within the soils of this area. The main reason was that concurrent $\mathrm{CO}_{2}$ and $\mathrm{CH}_{4}$ flux measurements nearly always showed a $\mathrm{CO}_{2} / \mathrm{CH}_{4}$ ratio lower than that measured in the fumarolic manifestations of the area, which are representative of the gas composition coming up from the geothermal system of the island. Such a pattern points to a loss of $\mathrm{CH}_{4}$ during the travelling of the gases within the soil towards the earth's surface. The aim of this work was to estimate the methane oxidation potential of the geothermal soils of Pantelleria through laboratory soil incubation experiments and to detect and characterise the methane-oxidising bacteria that thrive in these soils using culture-dependent and culture-independent approaches.

\section{Material and methods}

\subsection{Geological setting}

The island of Pantelleria is a strato-volcano located in the Strait of Sicily, about $100 \mathrm{~km} \mathrm{SW}$ of Sicily and $70 \mathrm{~km} \mathrm{NE}$ of Tunisia, on the axis of the Sicily Channel rift zone (Fig. 1). Pantelleria has a surface area of $83 \mathrm{~km}^{2}$, and it is entirely covered by volcanic products from both effusive and explosive 

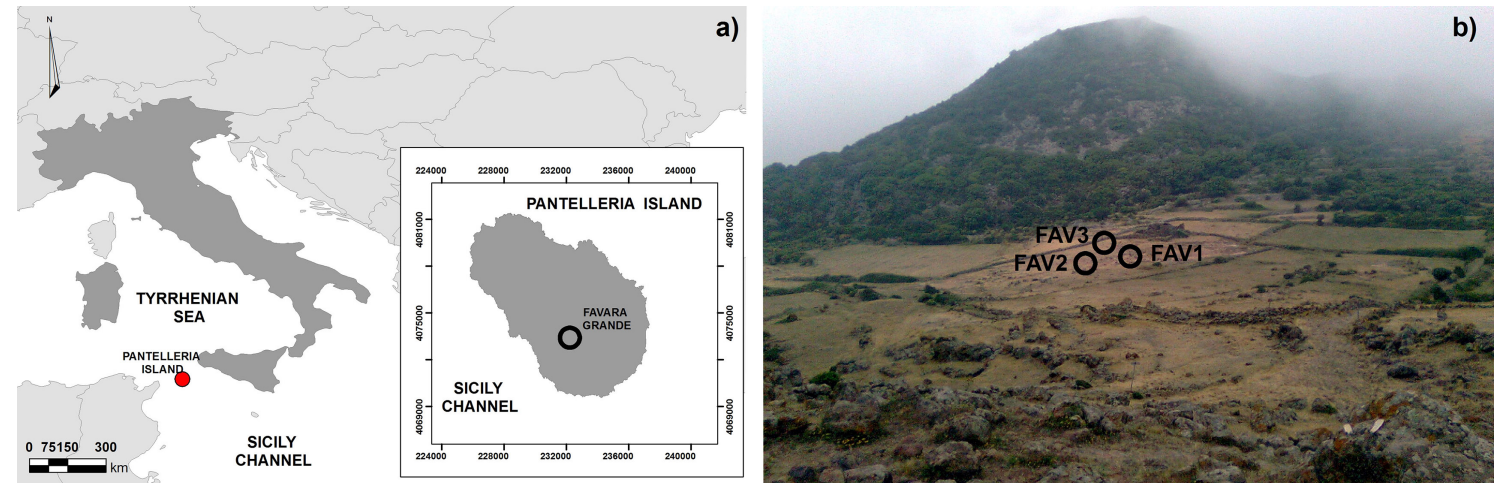

Figure 1. (a) Pantelleria (Italy) and (b) the three main sampling points at the geothermal field of Favara Grande.

activity, with dominant peralkaline rhyolites (pantellerites) and trachytes, and minor alkali basalts (Civetta et al., 1984). The most recent volcanic activity of the island was an underwater eruption in 1891, $4 \mathrm{~km} \mathrm{NNW}$ of its coast. Although at present in quiescent status, the widespread thermal manifestations on Pantelleria attest to a sustained heat flow (Parello et al., 2000). Many hot springs and thermal wells occur in the northwestern and southwestern parts of the island. Persistent fumaroles are concentrated on the young eruptive centres and/or along active faults. In the central part of the island, within the younger caldera, many fumaroles with temperatures between $40^{\circ} \mathrm{C}$ and $100^{\circ} \mathrm{C}$ are recognisable. Previous surveys identified many areas characterised by an intense gas flux from the soil (Chiodini et al., 2005). The most important fumarolic manifestations of the island can be detected at Le Favare, south of Montagna Grande (Fig. 1), an area located at the intersection of a regional tectonic lineament with many volcano-tectonic structures. It comprises the main fumarolic field of Favara Grande, with a strong steam emission and many fumarolic manifestations, all with temperatures close to boiling water. Fumarolic emissions have typical hydrothermal compositions (Chiodini et al., 2005; Fiebig et al., 2013) with water vapour as the main component (about $970 \mathrm{mmol} \mathrm{mol}^{-1}$ ) followed by $\mathrm{CO}_{2}$ (about $23 \mathrm{mmol} \mathrm{mol}^{-1}$ ). Among the minor components, the fumarolic gases of Favara Grande display relatively high contents of $\mathrm{H}_{2}$ and $\mathrm{CH}_{4}$ (about 1.30 and $0.80 \mathrm{mmol} \mathrm{mol}^{-1}$, respectively) and low contents of $\mathrm{H}_{2} \mathrm{~S}\left(<0.02 \mathrm{mmol} \mathrm{mol}^{-1}\right)$. This leads, after condensation of water vapour, to high $\mathrm{CH}_{4}$ concentrations in the soils (up to $44 \mathrm{mmol} \mathrm{mol}^{-1}$ ) and high $\mathrm{CH}_{4}$ fluxes from the soil (up to $221 \mathrm{mmol} \mathrm{m}^{-2} \mathrm{day}^{-1}$ ) in the area of Favara Grande (D'Alessandro et al., 2009).

\subsection{Soil sampling and chemical-physical characterisation}

Soil samples used in this study were collected at Favara Grande during two field campaigns in 2011 in an area that was previously ascertained to be the site of intense geothermal degassing (D’Alessandro et al., 2009). Top-soil samples
$(0-3 \mathrm{~cm})$ were collected in June 2011 from three sites (FAV1, FAV2 and FAV3), and a further sampling was carried out in November 2011 at site FAV2 on a vertical profile of 0 $13 \mathrm{~cm}$ (FAV2A to FAV2E) (Fig. 1, Table 1). Ground temperature measurements (at $2-50 \mathrm{~cm}$ in depth) were taken using thermal probes and a digital thermometer. All the soil samples used for geochemical and microbiological analyses were taken using a sterile hand shovel and stored in sterile plastic bags. Soil sub-samples for molecular analyses were stored at $-20^{\circ} \mathrm{C}$ until analysis. Soil sub-samples for geochemical analysis were air-dried overnight, sieved at $2 \mathrm{~mm}$, and homogenised. Organic matter in soils was measured by loss-onignition analysis with heating stages of $105^{\circ} \mathrm{C}$ for $4 \mathrm{~h}$ (for $\%$ of $\mathrm{H}_{2} \mathrm{O}$ by mass) and $400^{\circ} \mathrm{C}$ for $16 \mathrm{~h}$ (for $\%$ organic matter by mass) (Heiri et al., 2001); soil pH was determined using a $\mathrm{pH}$ meter in a mixture of $1 / 2.5$ of soil and distilled deionised water.

\subsection{Gas sampling and characterisation}

Soil gas samples from the three sites were taken through a special sampling device with three $2 \mathrm{~mm}$ ID tubes tapping soil gases at 13,25 and $50 \mathrm{~cm}$ in depth, using a gastight plastic syringe. The samples were collected sequentially from the shallowest to the deepest level. To avoid atmospheric contamination, the suction through the syringe is done very slowly ( $>60 \mathrm{~s}$ for $20 \mathrm{~mL}$ ). Two aliquots of about $20 \mathrm{~mL}$ of soil gas were extracted. The first was discarded and the second was injected through a three-way valve and a needle into a $12 \mathrm{~mL}$ pre-evacuated sampling vial (Exetainer ${ }^{\circledR}$, Labco Ltd). The overpressured vials were sent to the laboratory for $\mathrm{CH}_{4}, \mathrm{CO}_{2}, \mathrm{~N}_{2}, \mathrm{O}_{2}$ and $\mathrm{H}_{2}$ analysis by using a Perkin Elmer Clarus 500 GC equipped with Carboxen 1000 columns, two detectors (HWD and FID), and argon as the carrier gas. The gas samples were injected through an automated injection valve with a $1000 \mu \mathrm{L}$ loop. The introduction system of the GC (total volume about $2 \mathrm{~mL}$ ) was evacuated with a vacuum pump before the introduction of the sample, and was provided with a pressure sensor to correct small (positive or negative) deviations from the introduction 
Table 1. Chemical-physical characteristics of the soil sampled at the Favara Grande geothermal site (Pantelleria, Italy), and detection of the functional gene for methane monooxygenase $p m o A$. Thermal probe precision $\pm 0.01^{\circ} \mathrm{C} ; \mathrm{pH}$ meter precision $\pm 0.02 ; \mathrm{OM}_{\text {and }} \mathrm{H}_{2} \mathrm{O}$ precision $\pm 0.01 \%$.

\begin{tabular}{|c|c|c|c|c|c|c|c|}
\hline \multirow[t]{2}{*}{ Soil sample } & \multirow{2}{*}{$\frac{\text { Depth }}{\mathrm{cm}}$} & \multirow{2}{*}{$\frac{T^{\mathrm{a}}}{{ }^{\circ} \mathrm{C}}$} & \multirow[t]{2}{*}{$\mathrm{pH}$} & $\mathrm{OM}$ & $\mathrm{H}_{2} \mathrm{O}$ & \multicolumn{2}{|c|}{ Methane monooxygenase gene detection ${ }^{\mathrm{b}}$} \\
\hline & & & & \multicolumn{2}{|c|}{$\%$} & Proteobacterial $p m o A$ & Verrucomicrobial pmoA \\
\hline FAV1 & $0-3$ & 62 & 3.4 & 3.7 & 12.9 & $-{ }^{c}$ & - \\
\hline FAV2 & $0-3$ & 60 & 5.8 & 3.1 & 2.8 & $+{ }^{d}$ & + \\
\hline FAV3 & $0-3$ & 50 & 5.2 & 2.9 & 3.3 & + & - \\
\hline $\mathrm{FAV} 2 \mathrm{~A}^{\mathrm{e}}$ & $0-2$ & 33 & 6.6 & 2.3 & 2.5 & + & + \\
\hline FAV2B & $2-4$ & 37 & 6.7 & 6.2 & 2.7 & + & + \\
\hline FAV2C & $4-7$ & 46 & 6.6 & 1.8 & 3.1 & + & + \\
\hline FAV2D & $7-10$ & 74 & 6.0 & 1.9 & 4.3 & + & - \\
\hline FAV2E & $10-13$ & 83 & 5.9 & 1.9 & 6.0 & + & + \\
\hline
\end{tabular}

pressure (atmospheric) of the calibration standards. Calibration was made with certified gas mixtures. Analytical precision $( \pm 1 \sigma)$ was always better than $\pm 3 \%$. The detection limits were about $0.1 \mu \mathrm{mol} \mathrm{mol}^{-1}$ for $\mathrm{CH}_{4}, 2 \mu \mathrm{mol} \mathrm{mol}^{-1}$ for $\mathrm{H}_{2}, 10 \mu \mathrm{mol} \mathrm{mol}^{-1}$ for $\mathrm{CO}_{2}$ and $200 \mu \mathrm{mol} \mathrm{mol}^{-1}$ for $\mathrm{O}_{2}$ and $\mathrm{N}_{2}$.

\subsection{Methanotrophic activity}

The methane oxidation potential of the soils was analysed by transferring about $15 \mathrm{~g}$ of each air-dried soil sample in a $160 \mathrm{~mL}$ glass serum bottle that was capped with a rubber stopper and sealed with aluminium crimps, after wetting with $1 \mathrm{~mL}$ sterile distilled water. After sealing the bottle, the atmosphere was enriched in $\mathrm{CH}_{4}$ to reach about $1 \mathrm{mmol} \mathrm{mol}^{-1}$. Bottles were incubated at controlled room temperature (23$25^{\circ} \mathrm{C}$ ), and the $\mathrm{CH}_{4}$ concentration was measured on the same bottles at the beginning of the experiment and at about $24 \mathrm{~h}$ intervals for 5 days. To monitor the methane consumption better in samples that, after $24 \mathrm{~h}$, consumed more than $30 \%$ of the initial $\mathrm{CH}_{4}$, the experiments were repeated by measuring the concentrations at $2 \mathrm{~h}$ intervals. Samples collected in autumn from the FAV2 vertical profile were also incubated at $5,37,50$ and $80^{\circ} \mathrm{C}$ under the same conditions. Finally, the variation in the soil $\mathrm{CH}_{4}$ oxidation potential was analysed on sample FAV2A with different starting $\mathrm{CH}_{4}$ concentrations at room temperature (from about 0.1 to $85 \mathrm{mmol} \mathrm{mol}^{-1}$ ). Methane concentration inside the vials was measured using $\mathrm{CG}$ as above, withdrawing about $2 \mathrm{~mL}$ gas for each analysis. All incubation experiments were in duplicate and the results expressed as nmol $\mathrm{CH}_{4}$ per $\mathrm{g}$ of soil dry weight per $\mathrm{h}\left(\mathrm{nmol} \mathrm{g}^{-1} \mathrm{~h}^{-1}\right)$. To report methane oxidation potential to the dry weight of the soil, subsamples of the airdried soil were oven-dried at $105^{\circ} \mathrm{C}$. Taking into account all the instrumental errors, we consider that only values above $0.6 \mathrm{nmol} \mathrm{g}^{-1} \mathrm{~h}^{-1}$ indicate significant oxidation activity.

\subsection{Extraction of soil DNA}

The extraction of total DNA from soil samples was performed using the FastDNA ${ }^{\circledR}$ Spin Kit for Soil (MP Biomedicals, Solon, OH, USA), from $0.5 \mathrm{~g}$ of dried soil, following the manufacturer's protocol/instructions. The DNA quality and concentration were assessed with $1 \mathrm{X}$ TAE agarose gel (1\%) electrophoresis and spectrophotometric analysis using Nanodrop (NanoDrop ND-1000, Celbio SpA).

\subsection{Detection of methane oxidation genes and construction of a $p m o A$ gene library}

The gene encoding the key methane oxidation enzyme pMMO was detected by amplification of total soil DNA using the primers A189f and A682r (Holmes et al., 1995), targeting the $\beta$ subunit of the proteobacterial pmoA gene. PCRs were carried out in a final volume of $50 \mu \mathrm{L}$, containing $100 \mathrm{ng}$ of total DNA, $200 \mathrm{nM}$ of each oligonucleotide primer, $0.20 \mathrm{mM}$ dNTPs, and one unit of recombinant Taq polymerase, (Invitrogen, USA). The PCR program consisted of an initial denaturation step at $95^{\circ} \mathrm{C}$ for $4 \mathrm{~min}$, followed by 28 cycles consisting of a denaturation step at $95^{\circ} \mathrm{C}$ for $45 \mathrm{~s}$, annealing at $56^{\circ} \mathrm{C}$ for $45 \mathrm{~s}$, an extension at $72{ }^{\circ} \mathrm{C}$ for $45 \mathrm{~s}$, and a final extension at $72^{\circ} \mathrm{C}$ for $5 \mathrm{~min}$. For the $p m o A$ clone library, amplicons were purified using QIAquick spin columns (Qiagen, Germany) and cloned into PCRII TOPO-TA (Invitrogen, USA) according to the manufacturer's instructions. The ligation mixture was used to transform One Shot TOP10 chemically competent cells. Plasmids were extracted by using GenElute Plasmid Miniprep Kit (Sigma-Aldrich, USA) and screened for the correct-size insert by PCR 
amplification using vector-specific primers (M13F/M13R, supplied by the TOPO-TA cloning kit). Positive clones were sequenced using the universal T7 primer. The sequences of the $p m o A$ clones were deposited in Genbank under accession numbers KJ207214-19. Two novel couples of primers, 298f/599r (5'-CAGTGGATGAAYAGGTAYTGGAA3'/5'-ACCATGCGDTGTAYTCAGG-3') and 156f/743r (5'-TGGATWGATTGGAAAGATCG-3'/5'TTCTTTACCCAACGRTTTCT-3'), targeting Verrucomicrobial pmoAl/A2 and $p m o A 3$, respectively, were designed and positively validated on Methylacidiphilum fumarolicum strain SolV. To detect the Verrucomicrobial pmoA gene, PCR was carried out as described above using the OneTaq ${ }^{\circledR}$ DNA polymerase (New England Biolab, MA, USA), with an initial denaturation at $94{ }^{\circ} \mathrm{C}$ for $60 \mathrm{~s}$ followed by 5 cycles consisting of denaturation at $94^{\circ} \mathrm{C}$ for $30 \mathrm{~s}$, annealing at $57^{\circ} \mathrm{C}$ for $30 \mathrm{~s}$, and an extension at $68^{\circ} \mathrm{C}$ for $30 \mathrm{~s}$; the following 35 cycles consisted of a denaturation at $94^{\circ} \mathrm{C}$ for $30 \mathrm{~s}$, annealing at $52^{\circ} \mathrm{C}$ for $10 \mathrm{~s}$, and an extension at $68^{\circ} \mathrm{C}$ for $30 \mathrm{~s}$. A final extension at $68^{\circ} \mathrm{C}$ was carried out for $5 \mathrm{~min}$. Amplicons were purified and cloned into PCRII TOPO-TA (Invitrogen, USA) as described above. Clones containing an insert of the correct size were sequenced as described above.

\subsection{Isolation of methanotrophic bacteria}

In order to enrich soil microbial populations for methanotrophs, $15 \mathrm{~g}$ aliquots of FAV2 soil from the vertical profile 0 to $13 \mathrm{~cm}$ (samples FAV2A to FAV2E) were placed in $125 \mathrm{~mL}$ sealed serum bottles in an atmosphere supplemented with methane $(25 \%)$ and incubated either at $37^{\circ} \mathrm{C}$ or $65^{\circ} \mathrm{C}$ for 2 weeks. After incubation, two grams of enriched soil crumbles were transferred to $125 \mathrm{~mL}$ serum bottles containing $20 \mathrm{~mL}$ of low salt mineral medium M3 (Islam et al., 2008) adjusted to $\mathrm{pH} 6$ under the same conditions. After incubation, aliquots of M3 enrichment cultures were inoculated on M3 agar slants in $125 \mathrm{~mL}$ sealed serum bottles under a methane-enriched atmosphere and incubated as described above for 2 weeks. As soon as colonies appeared, they were transferred to a fresh medium to obtain pure cultures that were checked for methane consumption by GC analysis, as described above. Each isolate was routinely grown in M3 agar slants in $120 \mathrm{~mL}$ serum bottles, in an atmosphere enriched in methane $(25 \%)$ added every week, and transferred to a fresh medium every three weeks. Growth on alternative $\mathrm{C}$ sources was assessed by streaking each isolate on M3 agar plates containing methanol $(0.5 \%)$, glucose $(1 \%)$, fructose $(1 \%)$ and ethanol (1\%), respectively, and in the absence of any $\mathrm{C}$ source and incubating at $37^{\circ} \mathrm{C}$. The isolates were also incubated in $\mathrm{M} 3$ agar in a $\mathrm{CH}_{4}$ atmosphere at different temperatures. Genomic DNA was extracted from $10 \mathrm{~mL}$ of M3$\mathrm{CH}_{4}$ broth culture of each isolate grown in the conditions described above following the method described by Sambrook et al. (1989) and used as template for the amplification of the 16S rRNA gene with universal primers fD1/rD1 (Weisburg et al., 1991) and the pmoA gene, as described above. The 16S rRNA and pmoA gene sequences of the isolates were deposited in Genbank under accession numbers KJ20721014 and KJ207220, respectively. A growth curve of Methylocystis sp. strain Pan1 was obtained by pre-inoculating a single colony in a $125 \mathrm{~mL}$ serum bottle containing $10 \mathrm{~mL}$ of M3 mineral medium and $25 \%$ methane. The pre-culture was incubated for 10 days at $37^{\circ} \mathrm{C}$ to an $\mathrm{OD}_{600}$ of 0.25 , corresponding to $2.6 \times 10^{7} \mathrm{CFU} \mathrm{mL}{ }^{-1}$, and subsequently inoculated in three $160 \mathrm{~mL}$ serum bottles $(2 \mathrm{~mL}$ each) containing $20 \mathrm{~mL}$ of $\mathrm{M} 3$ mineral medium and $\sim 95 \mathrm{mmol} \mathrm{mol}^{-1}$ methane; growth was monitored as turbidity using a spectrophotometer $\left(\mathrm{OD}_{600}\right)$. Methane concentration was periodically measured in the cultures and in the uninoculated control bottles incubated under the same conditions.

\section{Results}

\subsection{Soil gas composition}

Soil gases collected in June 2011 at sites FAV1, FAV2 and FAV3 (Fig. 1, Table 1) display a composition that is the result of the mixing process between a hydrothermal component rich in $\mathrm{H}_{2}, \mathrm{CH}_{4}$ and $\mathrm{CO}_{2}$ and an atmospheric component rich in $\mathrm{O}_{2}$ and $\mathrm{N}_{2}$ (Table S1). The hydrothermal component coming from below is always enriched at the deeper sampling points, while the atmospheric component diffusing from above is enriched at the shallower soil levels. Although, at least at FAV1 and FAV2, at $50 \mathrm{~cm}$ in depth, the gas composition is very close to that of the fumarolic gases, $\mathrm{O}_{2}$ concentrations would still be enough to sustain aerobic methanotrophic activity (Kumaresan et al., 2011).

\subsection{Methanotrophic activity in the geothermal area}

Soils sampled from the three sites in the most active fumarolic area of Favara Grande show significant differences in chemical-physical parameters (Table 1 and Table S1). FAV1 has the highest temperature $\left(62^{\circ} \mathrm{C}\right.$ at $2 \mathrm{~cm}$ in depth) and the lowest $\mathrm{pH}$ (3.4); FAV2 is similar to FAV3, and both show significantly milder conditions than FAV1. Organic matter was in a range of 1.8 to $6.2 \%$ by mass, with the maximum value measured in the shallowest layer and decreased in the deeper layers. Water content was higher in the deeper layers, and decreasing in the shallowest layers (Table 1). Laboratory incubation experiments with soil samples from 0 to $3 \mathrm{~cm}$ detected $\mathrm{CH}_{4}$ consumption values in a range from 0.31 (FAV1) to $59.2 \mathrm{nmol} \mathrm{g}^{-1} \mathrm{~h}^{-1}$ (FAV2) (Fig. 2). Since FAV2 was the most active site, its methane oxidation was investigated further on a vertical profile up to a depth of $13 \mathrm{~cm}$ (Fig. 2). Temperature, in FAV2, increases with depth from $33^{\circ} \mathrm{C}$ to $83^{\circ} \mathrm{C}$ (November measurements), while $\mathrm{pH}$ decreases from 6.6 to 5.9. The maximum methane oxidation rate in the FAV2 vertical profile was measured in the shallowest soil layers $(0-2 \mathrm{~cm})$, but significant values $\left(6.23 \mathrm{nmol} \mathrm{g}^{-1} \mathrm{~h}^{-1}\right)$ were still detected at 


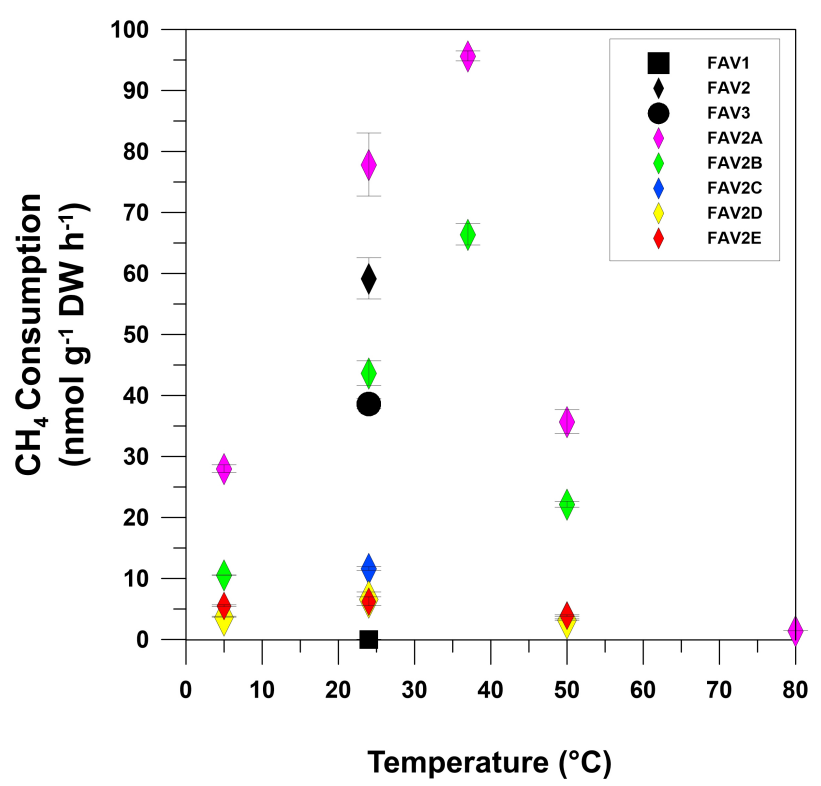

Figure 2. Methane consumption of soils sampled at sites FAV1, FAV2 and FAV3 (after incubation at controlled room temperature), and at different depths of FAV2 (soils incubated at different temperatures).

$13 \mathrm{~cm}$ in depth (Fig. 2). When samples from the vertical profile were incubated at different temperatures, the $\mathrm{CH}_{4}$ consumption increased with temperature from $5^{\circ} \mathrm{C}$ to a maximum at $37^{\circ} \mathrm{C}$, and then decreased to a minimum, but still detectable, methane consumption value at $80^{\circ} \mathrm{C}$ (Fig. 2). The methane oxidation potential of FAV2 soil strongly depends on the initial $\mathrm{CH}_{4}$ concentration in the headspace: methane oxidation values of $592 \mathrm{nmol} \mathrm{g}^{-1} \mathrm{~h}^{-1}$ are measured with an initial $\mathrm{CH}_{4}$ concentration of $85 \mathrm{mmol} \mathrm{mol}^{-1}$ at room temperature, and decrease to $8.17 \mathrm{nmol} \mathrm{g}^{-1} \mathrm{~h}^{-1}$, with a starting concentration of $0.15 \mathrm{mmol} \mathrm{mol}^{-1}$ (data not shown).

\subsection{Detection of methane oxidation genes}

The presence of methanotrophs was verified by detecting the unique methane oxidation gene in the total soil DNA extracted from the three sites FAV1, FAV2 and FAV3, and also in all the samples from the FAV2 vertical profile; PCR was carried out using the couple of primers targeting the pmoA gene encoding the $\beta$ subunit of the proteobacterial methane monooxygenase. A unique band of the expected size (580 bp, data not shown) was obtained from FAV2, FAV3 and all samples from the FAV2 vertical profile up to $13 \mathrm{~cm}$ in depth (Table 1). Conversely, no PCR product was obtained from FAV1 (Table 1). The two newly designed couples of primers targeting the three verrucomicrobial methane monooxygenase genes produced positive results only for FAV2 soil, where the primer couple 298f/599r (targeting pmoAl/A2) and the $156 \mathrm{f} / 743 \mathrm{r}$ couple (targeting pmoA3) yielded the expected PCR products of about 300 and $600 \mathrm{bp}$, respectively (data not shown) (Table 1). Accordingly, soil samples from the FAV2 profile showed the presence of verrucomicrobial methane monooxygenase genes, with the exception of FAV2D. No amplification products were obtained with the verrucomicrobial pmoA primers from FAV1 and FAV3.

\subsection{Diversity of methanotrophs at the FAV2 site}

In order to investigate the diversity of Proteobacterial methanotrophs at the most active site (FAV2), a pmoA gene library was constructed using the PCR product obtained from sample FAV2 (Table 1). The sequencing of twenty-six randomly chosen clone inserts from the pmoA TOPO-TA library revealed an abundance of Gammaproteobacterial methane monooxygenase genes distantly related to those of uncultured methanotrophic bacteria (82-90\% nt identity) and to the reference strain Methylococcus capsulatus bath $(82 \%$ nt identity) (Fig. 3). The closest sequences had been recently detected in a methanotrophic community of tropical alkaline landfill upland soils (Chang et al., 2010). Two of the Verrucomicrobial pmoA clones, obtained with the couple of primers targeting the pmoA3 gene (see above), were sequenced, and showed $99 \%$ identity with Methylacidiphilum fumarolicum strain SolV (Fig. 3).

\subsection{Isolation of methanotrophic bacteria from the FAV2 geothermal site}

In order to isolate methanotrophic bacteria from the geothermally active site, soil enrichment cultures were set in a methane-enriched atmosphere. After one week of growth, the cultures incubated at $37^{\circ} \mathrm{C}$ showed a visible increase in turbidity, while no growth was observed at $65^{\circ} \mathrm{C}$. Amplification of the proteobacterial $p m o A$ gene from the enrichment cultures at $37^{\circ} \mathrm{C}$ always gave positive results during the incubation period (data not shown). The amplification product of the last enrichment stage from the FAV2E soil sample was sequenced, and its sequence was close $(96 \%$ identity) to that of an uncultured Methylocystis (Fig. 3). Amplification of verrucomicrobial pmoA genes gave negative results since the first M3 enrichment step. The enrichment cultures were sub-cultured under the same conditions, and after streaking on M3 agar slants in sealed serum bottles with a $\mathrm{CH}_{4}$-enriched atmosphere, a few single colonies, apparently very similar to each other, were detected after 45 days. Three isolates were obtained from the three central layer soil samples $(2-10 \mathrm{~cm})$ and characterised further. The isolates were stably able to grow on methane, as the sole $\mathrm{C}$ sources could grow on methanol and were unable to grow on glucose, fructose and ethanol. Their $\mathrm{pH}$ range of growth was 3.5 to 8 , and they grew up to $45^{\circ} \mathrm{C}$, but were unable to grow at $65^{\circ} \mathrm{C}$. The $16 \mathrm{~S}$ rRNA gene sequence revealed that the three FAV2 isolates are all affiliated with the Alphaproteobacteria species Methylocystis parvus (99\% identity with Methylocystis parvus strain OBBP). The growth curve of 


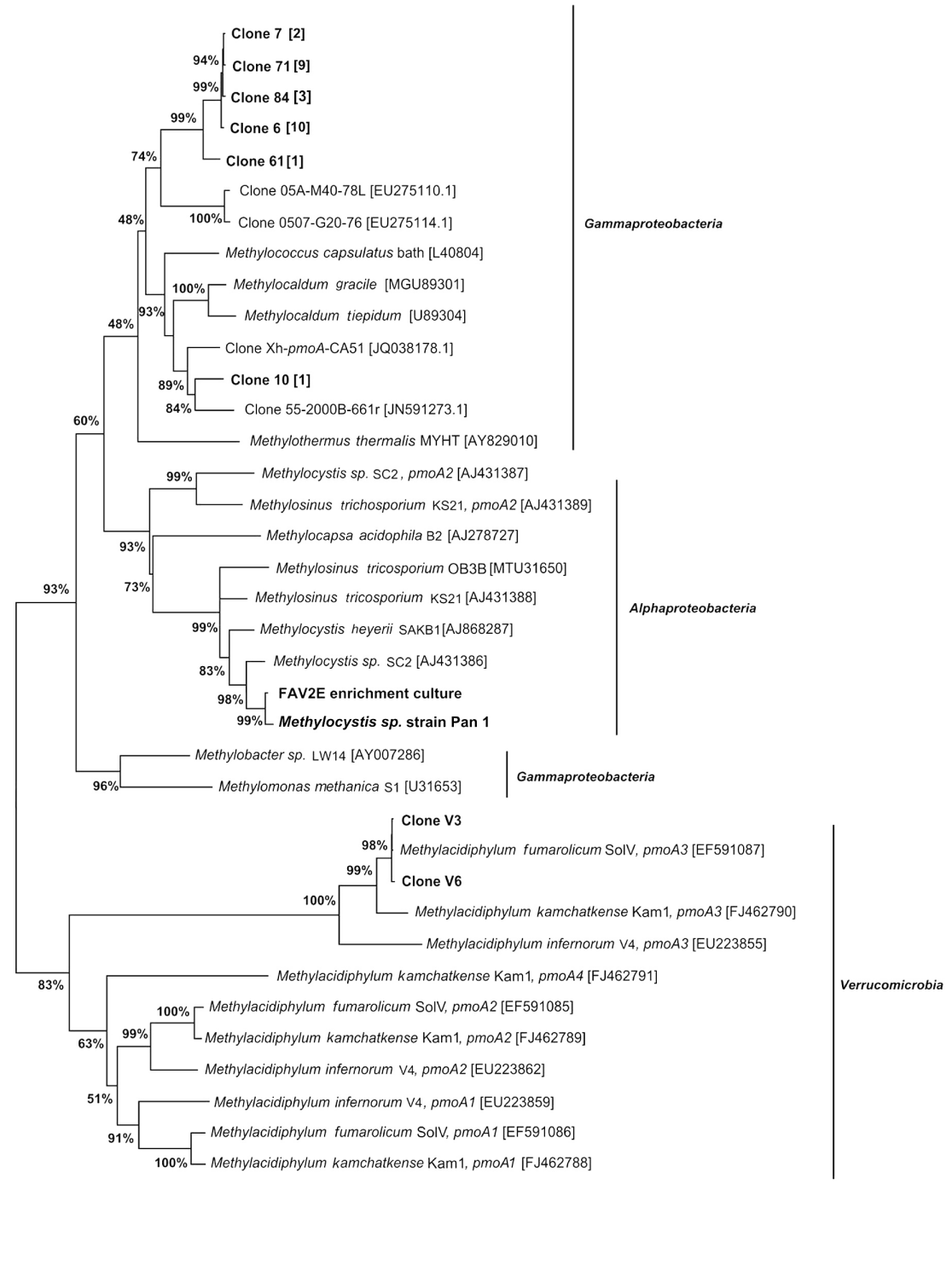

Figure 3. Phylogenetic tree constructed based on partial sequences (529 nt) of pmoA genes, showing the relative position of the genes and isolates from the FAV2 geothermal site where high methane oxidation rates were detected. The tree was constructed in the Molecular Evolutionary Genetics Analysis (MEGA) software version 4.0 (Tamura et al., 2007), and a maximum composite likelihood (MCL) model was used (Schmidt et al., 2002). A neighbour-joining distance correction method was applied. Node support values are indicated for the primary nodes. The scale bar represents a 0.05 change per position. FAV2E enrichment culture derives from amplification of the final stage of the enrichment; all the others are from the FAV2 soil clone library. Pan1 was isolated from the enrichment cultures, together with Pan2 and Pan3 (not shown); the total number of clones with identical sequences is indicated in square brackets.

Methylocystis parvus strain Pan1 indicates a correlation between methane consumption and turbidity and a methane oxidation on the order of $160 \mathrm{nmol}$ per hour $\mathrm{h}^{-1} \mathrm{~mL}^{-1}$ of culture (Fig. 4). Three other isolates, obtained from the methane enrichment cultures, were identified by $16 \mathrm{~S}$ rRNA gene (partial) sequencing. Two isolates from the enrichment culture of FAV2E were assigned to the facultative methanotroph Methylobacterium sp. (95\% identity) and to Brevibacillus agri (99\% identity), respectively. The isolate obtained from the enrichment culture of FAV2A was assigned to the Acidobac- terium genus (95\% identity) (data not shown). The cultures of Brevibacillus agri and Acidobacterium sp. appeared pure, based on cell morphology; however, they might be consortia of tightly syntrophic bacteria. These genera have already been detected in methane-rich environments in association with methanotrophs (Dedysh, 2009). Brevibacillus agri was already cultured from thermal features and has recently been reported as capable of growth on methane as the sole C source under thermophilic conditions, although methane is not its preferred substrate (Laursen et al., 2007). Sequences 


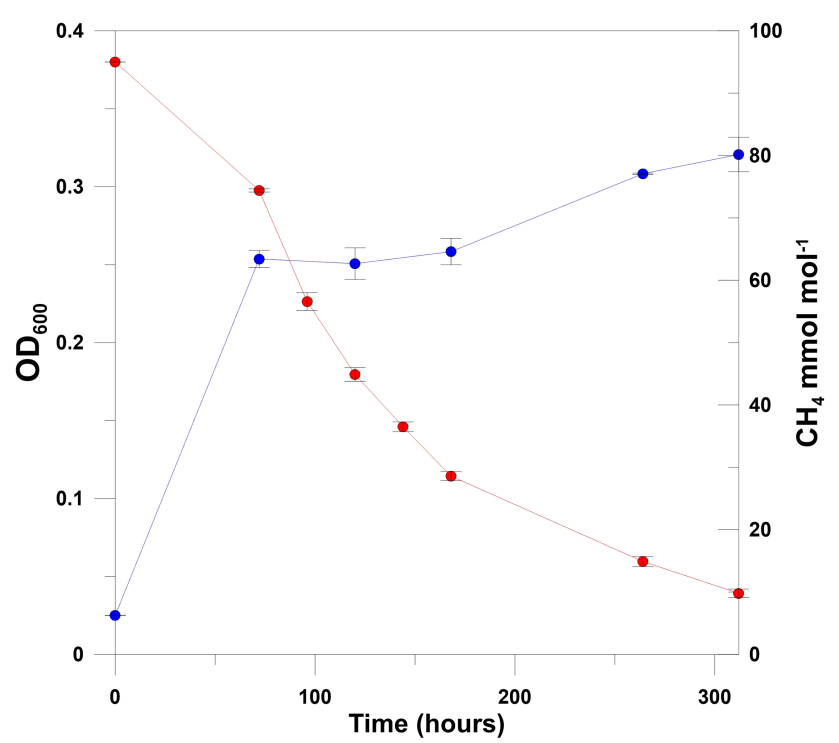

Figure 4. Growth (blue line) and corresponding variation of the methane in the headspace of the serum bottles as a result of methane consumption (red line) of the Pan1 Methylocystis sp. strain. The averages of the optical density measures $\left(\mathrm{OD}_{600}\right) \pm$ standard error are from three replicate $160 \mathrm{~mL}$ serum bottles incubated at $37^{\circ} \mathrm{C}$ at $\mathrm{pH}$ 5.8. No decrease in headspace methane was observed in uninoculated controls (data not shown).

related to the Acidobacteria phylum have been detected from the ${ }^{13} \mathrm{C}$ DNA during a stable isotope probing (SIP) experiment aiming to characterise the active methylotroph populations in forest soil microcosms (Radajewski et al., 2002).

\section{Discussion}

Pantelleria represents a high-enthalpy geothermal system, with petrological, structural and hydrothermal conditions that allow very high diffusive fluxes of geothermal gases enriched in methane (D'Alessandro et al., 2009; Parello et al., 2000). In this framework, Favara Grande represents the main exhalative area of Pantelleria, emitting about $2.5 \mathrm{Mg} \mathrm{a}^{-1}$ $\left(\mathrm{ta}^{-1}\right)$ of $\mathrm{CH}_{4}$ (D'Alessandro et al., 2009). At many sampling points of Favara Grande, $\mathrm{CO}_{2} / \mathrm{CH}_{4}$ ratios in the soil gases were higher than in the hydrothermal end members, revealing probable methanotrophic activity (D'Alessandro et al., 2009; Parello et al., 2000). Most of these sites corresponded to areas with low fluxes of hydrothermal gases towards the atmosphere and low concentrations of the same gases within the soil, probably allowing more efficient microbial oxidation. Instead, in the areas where the fumarolic gas fluxes were high, such as the presently studied sites FAV1, FAV2 and FAV3, the $\mathrm{CO}_{2} / \mathrm{CH}_{4}$ ratios in the soil gases up to a $13 \mathrm{~cm}$ depth were similar to those of the fumarolic emissions, and then they decreased in the shallowest soil layers. This indicates that the methanotrophic activity within the soil profile is strongly influenced by the hydrothermal upflow efficiency, which in turn affects soil environmental conditions. Many studies have highlighted the fact that aerobic methanotrophs increase their efficiency in very aerated soils, with high methane fluxes from the underground (Kip et al., 2012). A sustained hydrothermal gas upflow, as at sites FAV1, FAV2 and FAV3, saturates soils in fumarolic gases such as methane, and the air dilution is hampered. Under these conditions, the required amount of $\mathrm{O}_{2}$ for the aerobic methanotrophy is reached only in the shallowest soil layers. Measurements of the soil gases indicate a very high variation in concentrations of the atmospheric gas content $\left(\mathrm{O}_{2}\right.$ and $\left.\mathrm{N}_{2}\right)$ with depth. Air gas contributions at sites FAV2 and FAV3, where higher methane consumptions were measured, form more than $70 \%$ of the total gas content, creating a very favourable environment for methanotrophic bacteria and allowing atmospheric $\mathrm{O}_{2}$ to sustain the detected microbial $\mathrm{CH}_{4}$ oxidation.

The conditions detected at Favara Grande thus appear favourable for methanotrophs, which were actually detected by culture-independent methods at sites FAV2 and FAV3. These sites have high temperatures (up to $60^{\circ} \mathrm{C}$ at $2 \mathrm{~cm}$ in depth) and are only slightly acidic; incubation experiments point out the highest methanotrophic activity in the shallowest soil layers at FAV2 and FAV3, with rapid decreases with depth. The oxidation potential in the deepest layer (10$13 \mathrm{~cm})$ is probably too low $\left(6.23 \mathrm{nmol} \mathrm{g}^{-1} \mathrm{~h}^{-1}\right)$ to affect the $\mathrm{CO}_{2} / \mathrm{CH}_{4}$ ratio significantly at the deepest sampling point (FAV2E). Chemical-physical analysis and total bacterial diversity analysed by TTGE (Supplement, Fig. S1) suggest that sites FAV2 and FAV3 have very similar environmental conditions and microbial diversity. At both sites, proteobacterial methane monooxygenase genes were detected, although verrucomicrobial pmoA was only detected at FAV2. Negligible methane oxidation at site FAV1 seems in accordance with the negative results obtained by molecular probing of $p m o A$ genes, and is probably due to high temperatures, low $\mathrm{pH}$, low oxygen availability and chemical conditions at FAV1 that prevent survival of even the most thermophilic Verrucomicrobia. The thermo-acidic geothermal soils, where methanotrophic Verrucomicrobia were isolated for the first time, showed high methane fluxes (Castaldi and Tedesco, 2005), low $\mathrm{pH}$ (up to 1) and high temperatures of up to $70^{\circ} \mathrm{C}$ (Pol et al., 2007), although the isolation conditions were milder $\left(\mathrm{pH} 2\right.$ and a temperature of $55^{\circ} \mathrm{C}$ ) than those detected in situ. The extreme physical-chemical conditions, however, do not prevent bacterial life at FAV1, as the TTGE (Fig. S1) analysis of the bacterial 16S rRNA-amplified gene describes a lowcomplexity bacterial community that thrives in FAV1 soil. This community probably does not include (known) methanotrophs, but could coexist with a more complex archaeal community (Kan et al., 2011).

Enrichment cultures with methane as the sole $\mathrm{C}$ and energy source and culture-independent techniques based on functional gene probes were used to describe the diversity of methanotrophs at the most active site (FAV2). Matching the 
results obtained from the pmoA gene library and the isolation by enrichment cultures on the soil profile, the FAV2 site at Favara Grande recorded the highest diversity of methanotrophs ever described in a geothermal soil (Op den Camp et al., 2009; Kizilova et al., 2013). In the same soil, in fact, we could isolate and cultivate in pure culture type II Alphaproteobacterial methanotrophs of the genus Methylocystis and, contemporarily, we detected, by amplification of the functional methane monooxygenase gene pmoA, as yet uncultivated methanotrophic Gammaproteobacteria related to Methylococcus capsulatus and Methylocaldum spp.

As standard primers are not adequate for detecting pmoA genes in Verrucomicrobia, two new couples of primers were specifically designed on the consensus sequences of known Verrucomicrobia pmoA genes. Using the newly designed primers, we were able to detect the presence of Verrucomicrobial methane monooxigenase genes of Methylacidiphilum fumarolicum SolV, isolated for the first time at Solfatara di Pozzuoli in Italy (Pol et al., 2007). This is as extraordinarily high a diversity of methanotrophs as could ever be expected in a geothermal soil, and this is the first report in which the presence of both phyla of methanotrophs, Proteobacteria and Verrucomicrobia, is recorded and their coexistence demonstrated. Interestingly, the results obtained from the $p m o A$ gene libraries do not overlap with those from enrichment cultures. Gammaproteobacterial and verrucomicrobial methane monooxygenase were only detected in the clone library from soil DNA, while only Alphaproteobacteria type II methanotrophs could be isolated after enrichment in a highly concentrated methane atmosphere at $37^{\circ} \mathrm{C}$. This would indicate a preponderance of the most thermo-tolerant Gammaproteobacterial methanotrophs close to the Methylococcus and Methylocaldum genera (Hanson and Hanson, 1996; Trotsenko et al., 2002) in the geothermal FAV2 soil.

These as yet uncultivated Type I methanotrophs are probably responsible for methanotrophy in the shallowest soil layer, but also in the hottest deeper layers. Type I methanotrophs are reported as being dominant in environments that allow the most rapid growth, while type II methanotrophs are more abundant in environments with fluctuating nutrient availability (Hanson and Hanson, 1996). Type I pmoA sequences, however, could be preferentially amplified over those from type II methanotrophs due to variations in the guanine and cytosine content of their DNA (Murrell and Jetten, 2009). Type II methanotrophs in fact could not be detected by molecular methods, but resulted as the dominant cultivable methanotrophs in the top $10 \mathrm{~cm}$ soil layers. Under laboratory conditions in the presence of high methane concentrations at $37^{\circ} \mathrm{C}$, type II methanotrophs, which tend to survive more, took precedence over the other methanotrophs (both Gammaproteobacteria and Verrucomicrobia).

The conditions used in this study for the enrichment culture setting, actually were those described for the isolation of methanotrophic Verrucomicrobia by Islam and colleagues (2008); following their procedure, the medium $\mathrm{pH}$ was ad- justed to 6 (instead of 3.5) in order to restore the FAV2 soil condition, but we were unable to isolate any verrucomicrobial member, although they were detected by molecular methods in the same soil samples. Cultivation of Verrucomicrobia methanotrophs under laboratory conditions is hard to obtain, and seems to be limited by still unknown factors. New knowledge of the positive role of rare earth elements (REE) in Verrucomicrobia methanotroph growth and cultivation was recently provided by Pol et al. (2014). They suggested that a good strategy for cultivating Verrucomicrobia methanotrophs could be the addition of REE in the culture media. In fact, recently it was demostrated that lantanides are essential cofactors of homodimeric methanol dehydrogenase by providing superior catalytic properties to pyrroloquinoline quinone (PQQ) dependent methanol dehydrogenase, which is a key enzyme for both methanotrophs and methylotrophs (Pol et al., 2014).

Pantelleria soils naturally contain REE (Gagliano, 2014), but have higher $\mathrm{pH}$ values with respect to the soils of Solfatara, where the Verrucomicrobia (Pol et al., 2007; Pol et al., 2014) were isolated. Soil acidity strongly increases REE mobility and consequently their availability to soil microbes (Grawunder and Merten, 2012). Due to the relatively high $\mathrm{pH}$ of the soil collected at FAV2 and, consequently, of the M3 medium used for enrichment cultures, REE could have been limiting for the growth of Verrucomicrobia methanotrophs in the M3 culture medium.

A high $\mathrm{CH}_{4}$ concentration and a temperature of $37^{\circ} \mathrm{C}$ favoured growth of Methylocystis from the first top soil layers and the facultative Methylobacterium in the deepest layer. Methylocystis is one of the most ubiquitous genera, being capable of oxidising methane both in high and low amounts (Kip et al., 2012) and under acidic pH (Op den Camp et al., 2009). Our Methylocystis isolates Pan $1, \operatorname{Pan} 2$ and Pan 3 show a wider $\mathrm{pH}$ range (from 3.5 to 8.0) and a higher temperature limit $\left(>40^{\circ} \mathrm{C}\right.$ ) than those described for this genus (Kizilova et al., 2013). These Methylocystis isolates could contribute to methane oxidation in the shallowest soil layers up to $7 \mathrm{~cm}$, characterised by $T<46^{\circ} \mathrm{C}$ and almost neutral $\mathrm{pH}$.

No isolates, instead, could be obtained from enrichments at $65^{\circ} \mathrm{C}$, even though methanotrophic activity was detected in soils up to $80^{\circ} \mathrm{C}$. It can be argued that methanotrophy at higher temperatures could be sustained by the as yet uncultured (and perhaps unculturable) methanotrophs, as those detected by culture-independent methods that are distantly related to the thermophilic genera Methylocaldum and Methylococcus.

Most $p m o A$ sequences show very low identity with other methanotrophs, indicating that Pantelleria geothermal soils host new species of thermophilic methanotrophs that are adapted to these specific site conditions. Different groups of methanotrophs are generally associated with their ability to survive, grow and oxidise methane in different environments. While the presence of Verrucomicrobia in a geothermal soil was predictable due to their thermophilic 
and acidophilic character, the presence of both Alpha- and Gamma-proteobacteria was unexpected, and suggests that high $\mathrm{CH}_{4}$ fluxes and differences in environmental conditions shape the complex methanotroph community structure in this geothermal area.

This study on Pantelleria soils suggests that a physiologically and taxonomically diverse group of methanotrophs is responsible for $\mathrm{CH}_{4}$ consumption at FAV2 on a layer of $0-13 \mathrm{~cm}$ and, presumably, at the FAV3 site; at the same time, our results assess that temperatures above $80^{\circ} \mathrm{C}$ hinder methane oxidation and probably the survival of methanotrophs. While methanotrophic Verrucomicrobia are reported as dominating highly acidic geothermal sites, our results indicate that slightly acidic soils, in high-enthalpy geothermal systems, host a more diverse group of both culturable and uncultivated methanotrophs. This report contributes to a better understanding of the ecology of methanotrophy at geothermal sites and its impact in atmospheric chemistry.

\section{The Supplement related to this article is available online at doi:10.5194/bg-11-5865-2014-supplement.}

Acknowledgements. We acknowledge S. Cappello for bioinformatics support, A. Pol for supplying Methylacidiphilum fumarolicum SolV used for primer testing, D. Monaghan for helping in biomolecular analysis and F. Salerno for helping in gas chromatography. This work is part of the $\mathrm{PhD}$ thesis research of the first author $(\mathrm{PhD}$ in Geochemistry - University of Palermo 24th cycle).

Edited by: Z. Jia

\section{References}

Ait-Benichou, S., Jugnia, L. B., Greer, C. W., and Cabral, A. R.: Methanotrophs and methanotrophic activity in engineered landfill biocovers, Waste Manage., 29, 2509-2517, 2009.

Cardellini, C., Chiodini, G., Frondini, F., Granieri, D., Lewicki, J., and Peruzzi, L.: Accumulation chamber measurements of methane fluxes: application to volcanic-geothermal areas and landfills, Appl. Geochem., 18, 45-54, 2003.

Castaldi, S. and Tedesco, D.: Methane production and consumption in an active volcanic environment of Southern Italy, Chemosphere, 58, 131-139, 2005.

Chang, C. Y., Tung, H. H., Tseng, I. C., Wu, J. H., Liu, Y. F., and Lin, H. M.: Dynamics of methanotrophic communities in tropical alkaline landfill upland soil Agr. Ecosyst. Environ., Appl. Soil Ecol., 46, 192-199, 2010.

Chiodini, G., Granieri, D., Avino, R., Caliro, S., and Costa, A.: Carbon dioxide diffuse degassing and estimation of heat release from volcanic and hydrothermal systems. J. Geophys. Res., 110, B08204, doi:10.1029/2004JB003542, 2005.
Civetta, L., Cornette, Y., Crisci, G., Gillot, P. Y., Orsi, G., and Requejo, C. S.: Geology, geochronology and chemical evolution of the island of Pantelleria, Geol. Mag., 121, 541-562, 1984.

D’Alessandro, W., Bellomo, S., Brusca, L., Fiebig, J., Longo, M., Martelli, M., Pecoraino, G., and Salerno, F.: Hydrothermal methane fluxes from the soil at Pantelleria island (Italy), J. Volcanol. Geoth. Res., 187, 147-157, 2009.

D’Alessandro, W., Brusca, L., Kyriakopoulos, K., Martelli, M., Michas, G., Papadakis, G., and Salerno, F.: Diffuse hydrothermal methane output and evidence of methanotrophic activity within the soils at Sousaki (Greece), Geofluids, 11, 97-107, 2011.

Dedysh, S. N.: Exploring methanotroph diversity in acidic northern wetlands: molecular and cultivation-based studies, Microbiology, 78, 655-669, 2009.

Dunfield, P. F., Yuryev, A., Senin, P., Smirnova, A. V., Stott, M. B., Hou, S., Ly, B., Saw, J. H., Zhou, Z., Ren, Y., Wang, J., Mountain, B. W., Crowe, M. A., Weatherby, T. M., Bodelier, P. L. E., Liesack, W., Feng, L., Wang, L., and Alam, M.: Methane oxidation by an extremely acidophilic bacterium of the phylum Verrucomicrobia, Nature, 06411, 879-882, 2007.

Dutaur, L. and Verchot, L. V.: A global inventory of the soil $\mathrm{CH}_{4}$ sink, Global Biogeochem. Cy., 21, GB4013, doi:10.1029/2006GB002734, 2007.

Etiope, G. and Klusman, R. W.: Geologic emissions of methane to the atmosphere, Chemosphere, 49, 777-789, 2002.

Etiope, G. and Klusman, R. W.: Microseepage in drylands: flux and implications in the global atmospheric source/sink budget of methane, Global Planet. Change, 72, 265-274, 2010.

Etiope, G., Fridriksson, T., Italiano, F., Winiwarter, W., and Theloke, J.: Natural emissions of methane from geothermal and volcanic sources in Europe, J. Volcanol. Geoth. Res., 165, 7686, 2007.

Etiope, G., Lassey, K. R., Klusman, R. W., and Boschi, E.: Reappraisal of the fossil methane budget and related emission from geologic sources, Geophys. Res. Lett., 35, L09307, doi:10.1029/2008GL033623, 2008.

Fiebig, J., Tassi, F., D’Alessandro, W., Vaselli, O., and Woodland, A. B.: Carbon-bearing gas geothermometers for volcanichydrothermal systems, Chem. Geol., 351, 66-75, 2013.

Gagliano, A. L.: Gaseous emissions from geothermal and volcanic areas: focus on methane and methanotrophs, $\mathrm{PhD}$ thesis, University of Palermo, 2014.

Grawunder, A., and Merten, D.: Rare earth elements in acidic systems - biotic and abiotic impacts, Soil Biol., 31, 81-97, 2012.

Hanson, R. S. and Hanson, T. E.: Methanotrophic bacteria, Microbiol. Rev., 60, 439-471, 1996.

Heiri, O., Lotter, A. F., and Lemcke, G.: Loss-on-ignition as a method for estimating organic and carbonate content in sediments: reproducibility and comparability of results, J. Paleolimnol., 25, 101-110, 2001.

Holmes, A. J., Costello, A., Lidstrom, M. E., and Murrel, J. C.: Evidence that participate methane monooxygenase and ammonia monooxygenase may be evolutionarily related, FEMS Microbiol. Lett., 132, 203-208, 1995.

Houghton, J. T., Ding, Y., Griggs, D. J., Noguer, M., van der Linden, P. J., Dai, X., Maskell, K., and Johnson, C. A.: Intergovernmental Panel on Climate Change The Scientific Basis. Cambridge University press, (Eds.), 2001. 
Islam, T, Jensen, S., Reigstad, L. J., Larsen, Ø., and Birkeland, N. K.: Methane oxidation at $55^{\circ} \mathrm{C}$ and $\mathrm{pH} 2$ by a thermoacidophilic bacterium belonging to the Verrucomicrobia phylum, $\mathrm{P}$. Natl. Acad. Sci. USA, 105, 300-304, 2008.

Kan, J., Clingenpeel, S., Macur, R. E., Inskeep, W. P., Lovalvo, D., Varley, J., Gorby, Y., McDermott, T. R., and Nealson, K.: Archea in Yellostone Lake, ISME J., 5, 1784-1795, 2011.

Khadem, A. F., Pol, A., Wieczorek, A., Mohammadi, S. S., Francoijs, K. J., Stunnenberg, H. G., Jetten, M. S., and Op den Camp, H. J.: Autotrophic methanotrophy in verrucomicrobia: Methylacidiphilum fumariolicum SolV uses the Calvin-BensonBassham cycle for carbon dioxide fixation., J. Bacteriol., 193, 4438-4446, 2011.

Kip, N., Fritz, C., Langelaan, E. S., Pan, Y., Bodrossy, L., Pancotto, V., Jetten, M. S. M., Smolders, A. J. P., and Op den Camp, H. J. M.: Methanotrophic activity and diversity in different Sphagnum magellanicum dominated habitats in the southernmost peat bogs of Patagonia, Biogeosciences, 9, 47-55, doi:10.5194/bg-9-47-2012, 2012.

Kizilova, A. K., Sukhacheva, M. V., Pimenov, N. V., Yurkov, A. M., Kravchenko, I. K.: Methane oxidation activity and diversity of aerobic methanotrophs in $\mathrm{pH}$-neutral and semi-neutral thermal springs of the Kunashir Island, Russian Far East, Extremophiles, 18, 207-218, doi:10.1007/s00792-013-0603-z, 2013.

Kumaresan, D., Héry, M., Bodrossy, L., Singer, A. C., StralisPavese, N., Thompson, I. P., and Murrell, J. C.: Earthworm activity in a simulated landfill cover soil shifts the community composition of active methanotrophs, Res. Microbiol., 162, 1027-1032, 2011

Laursen, A. E., Kulpa, C. F., Niedzielski, M. F., Estable, M. C.: Bacterial cultures capable of facultative growth on methane under thermophilic or thermotolerant conditions, J. Environ. Eng. Landsc., 6, 643-650, 2007.

McDonald, I. R., Bodrossy, L., Chen, Y., and Murrell, J. C.: Molecular ecology techniques for the study of aerobic methanotrophs, Appl. Environ. Microb., 74, 1305-1315, 2008.

Murrell, C. J. and Jetten, M. S. M.: The microbial methane cycle, Environ. Microbiol. Reports, 1, 279-284, 2009.

Op den Camp, H. J. M., Islam, T., Stott, M. B., Harhangi, H. R., Hynes, A., Schouten, S., Jetten, M. S. M., Birkeland, N. K., Pol, A., and Dunfield, P. F.: Environmental, genomic and taxonomic perspectives on methanotrophic Verrucomicrobia, Environ. Microbiol. Reports, 1, 293-306, 2009.

Parello, F., Allard, P., D'Alessandro, W., Federico, C., JeanBaptiste, P., and Catani, O.: Isotope geochemistry of Pantelleria volcanic fluids, Sicily Channel rift: a mantle volatile end-member for volcanism in southern Europe, Earth Planet. Sc. Lett., 180, 325-339, 2000.
Pol, A., Heijmans, K., Harhangi, H. R., Tedesco, D., Jetten, M. S. M. and Op den Camp, H. J. M.: Methanotrophy below pH 1 by a new Verrucomicrobia species, Nature, 450, 874-878, 2007.

Pol, A., Barends, T. R., Dietl, A., Khadem, A. F., Eygensteyn, J., Jetten, M. S., and Op den Camp, H. J.: are earth metals are essential for methanotrophic life in volcanic mudpots, Environ. Microbiol., 16, 255-264, 2014.

Radajewski, S., Webster, G., Reay, D. S., Morris, S. A., Ineson, P., Nedwell, D. B., Prosser, J. I., and Murrell, J. C.: Identification of active methylotroph populations in an acidic forest soil by stable isotope probing, Microbiology, 148, 2331-2342, 2002.

Rahalkar, M., Deutzmann, J., Schink, B., and Bussmann, I.: Abundance and activity of methanotrophic bacteria in littoral and profundal sediment of lake Constance (Germany), Appl. Environ. Microb., 75, 119-126, 2009.

Reeburgh, W. S.: Global methane biogeochemistry, in: The Atmosphere, edited by: Holland, H. D., Turekian, K. K., 2003.

Sambrook, J., Fritsch, E. F., and Maniatis, T. A.: Molecular Cloning: a Laboratory Manual, 2nd edn., Cold Spring Harbor Laboratory Press, Cold Spring Harbor, USA, 1989.

Schmidt, H. A., Strimmer, K., Vingron, M., and von Haeseler, A.: TREE-PUZZLE: maximum likelihood phylogenetic analysis using quartets and parallel computing, Bioinformatics, 18, 502504, 2002.

Tamura, K., Dudley, J., Nei, M., and Kumar, S.: MEGA4: Molecular Evolutionary Genetics Analysis (MEGA) software version 4.0, Mol. Biol. Evol., 24, 1596-1599, 2007.

Trotsenko, Y. A. and Khmelenina, V. N.: Biology of extremophilic and extremotolerant methanotrophs, Arch. Microbiol., 177, 123$31,2002$.

Weisburg, W. G., Barns, S. M., Pelletier, D. A., and Lane, D. J.: 16S ribosomal DNA amplification for phylogenetic study, J. Bacteriol., 173, 697-703, 1991.

Wise, M. G., McArthur, J. V., and Shimkets, L. J.: Methanotroph diversity in landfill soil: isolation of novel type I and type II methanotrophs whose presence was suggested by cultureindependent 16S ribosomal DNA analysis, Appl. Environ. Microb., 65, 4887-4897, 1999. 